\title{
PANDANGAN HUKUM ISLAM TERHADAP FATWA DEWAN SYARI'AH NASIONAL-MAJLIS ULAMA INDONESIA NO.77/DSN-MUI/IV/2010 TENTANG JUAL BELI EMAS SECARA KREDIT
}

\author{
M. Najamuddin Aminullah \\ Sekolah Tinggi Ilmu Tarbiyah (STIT) Darussalimin NW Praya \\ Email: Mnajamudinaminullah6@ gmail.com
}

\begin{abstract}
Abstrak: Penelitian ini bertujuan untuk mengetahui hukum jual beli emas secara kredit yang difatwakan Dewan Syari'ah Nasional. Jenis penelitian ini adalah penelitian kepustakaan dengan data-data berupa undang-undang atau fatwa, pendapat ulama, qur'an dan hadist dan simber data lainnya yang berkaitan dengan jual beli emas secara kredit. Metode penelitian ini menggunakan metode analisis, yaitu memaparkan teori-teori jual beli, larangan-larangan jual beli dan pendapat para ulama. Fatwa Dewan Syari'ah Nasional tidak bertentangan dengan hukum Islam sebagaimana anggapan banyak pihak yang mendasarkan pendapat mereka pada keumuman dalil-dalil tentang riba' pada emas Emas dalam perkembangannya tidak lagi dipandang sebagai mata uang (tsaman), tetapi lebih sebagai barang dagangan atau perhiasan (sil'ah) selain itu emas harganya lebih stabil sehingga tidak sedikit masyarakat yang menjadikan sebagai objek investasi.
\end{abstract}

Kata Kunci: Emas, Kredit \& Dewan Syari'ah Nasional

\begin{abstract}
This study aims to determine the law of buying and selling gold on credit that is imposed by the National Syari'ah Council. This type of research is literature research with data in the form of laws or fatwas, opinions of scholars, qur'an and hadiths and other data sources related to buying and selling gold on credit. This research method uses analytical methods which describes the theories of buying and selling, buying and selling prohibitions and the opinions of the scholars. The fatwa of the National Shari'ah Council does not contradict with Islamic law which the opinion base on the generality of the arguments about usury 'on gold Gold in its development is no longer seen as currency (tsaman), but more as merchandise or jewelry (sil'ah) besides that, the price of gold is more stable so that not a few people make it an object of investment.
\end{abstract}

Keywords: Gold, Credit, and National Syari'ah Council 


\section{PENDAHULUAN}

Munculnya permasalahan ummat dalam bidang mu'amalah bersumber dari kenyataan bahwa manusia mempunyai kebutuhan yang sangat banyak, dimana sarana untuk memenuhi kebutuhan tersebut sifatnya sangat terbatas. Sekiranya sarana pemenuhan kebutuhan tersebut seiring dengan kebutuhan manusia.

Jual beli merupakan kegiatan yang sakral karena mengandung peran penting dalam pemenuhan kebutuhan yang begitu besar. Namun, dibalik perannya yang begitu sentral tersebut, manusia sebagai subjek pelaku jual beli sering kali melakukan hal-hal tujuan dalam memenuhi kebutuhan tersebut.Oleh karena itu, dalam Islam diperlakukan aturan main dan ketentuanketentuan bagaimana harusnya jual beli itu dilakukan. Dimulai dari firman Allah SWT yang menjelaskan bahwa jual beli adalah halal

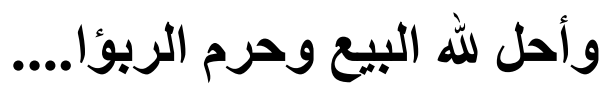

\section{Artinya: "dan Allah telah menghalalkan jual beli dan mengharamkan riba", (Al- Baqarah (2): 275).}

Allah swt. Telah mensyari'atkan dan menghalalkan jual beli bagi hamba-hambanya karena suatu hikmah, untuk pemenuhan kebutuhan seorang hamba yang niscaya saling membutuhkan satu sama lain. Artinya, seorang manusia tidak akan bisa memenuhi kebutuhan sendiri tanpa pangku tangan orang lain. Dan jalan untuk memenuhi kebutuhan tersebut adalah jual beli (Abdurahman AsSa'di, 2008: 260).

Selanjutnya Rasulullah SAW juga memberikan penjelasan lebih luas terkait jual beli melalui hadits-haditsnya sekaligus memperkuat dalil mengenai hal tersebut. Diantaranya, hadits yang diriwayatkan oleh Rafa'ah Bin Rafi' yang menjelaskan bahwa jual beli adalah kegiatan yang dinilai baik. Atas dasar hikmah itu juga, ijmak para ulama' menyepakati akan adannya jual beli sebagai kegitan mu'amalah di tengah kehidupan yang dinilai baik yang kemudian dituangkan dalam kaidah fiqh:

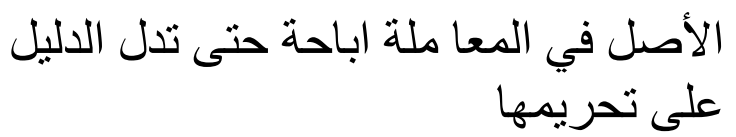

Artinya : Pada mulanya dalam mu'amalah adalah boleh sebelum ada dalil atas keharamannya (Ahmad Djazuli, 2001: 130)

Seiring dengan perkembangan zaman, praktik jual beli mengalami banyak perkembangan bentuk transaksi karena kemajuan perekonomian yang sangat pesat. Salah satu contoh adalah jual beli kredit yang merupakan salah satu perkembangan transaksi yang banyak dilakukan oleh para pelaku ekonomi.

Secara fiqh, jual beli kredit (al-bai' bi tsamanin 'ajil atau bai'at at-taqsith) berarti “ suatu akad transaksi dengan cara berhutang atau mencicil” artinya, penjual menyerahkan barang yang dijualnya kepada pembeli dengan harga yang disepakati bersama, tetapi pembayaran harganya tidak secara tunai, 
melainkan ditangguhkan sampai pada waktu yang sampai pada waktu yang ditentukan sesuai kesepakatan. Terkadang penjual menerima sebagian harganya secara tunai (lebih dahulu), sedang sisanya dibayar berangsur. Jual beli yang demikian yaitu termasuk kedalam dua jual beli dalam satu akad atau transaksi yang termasuk kedalam jual beli yang dilarang. Larangan tersebut berdasarkan hadits Nabi yang diriwayatkan oleh Imam Ahmad dari Abu Hurairah;

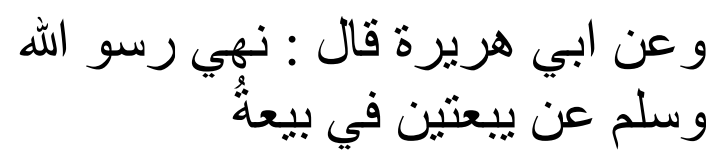

Secara zahir, hadist tersebut melarang dua jual beli dalam dalam satu akad atau transaksi yaitu dengan pembayaran tunai dan kredit yang banyak terjadi pada masa sekarang ini. Namun kenyataan tersebut tidak dapat dihindari karena para pelaku usaha atau perusahaan yang ada di Indonsesia sudah menerapkan penjualan dengan cara yang demikian, mulai dari bahan pokok, pakaian, alat eletronik maupun kebutuhan-kebutuhan yang lain yang dalam transaksinya dengan cara tunai dan kredit.

Namun seperti yang telah kita maklumi jual beli barang secara tunai di perkenankan, maka juga jual beli dengan pembayaran kemudian. Pembayaran kemudian ini dilakukan sesuai dengan tenggang waktu yang disepakati bersama, maupun dilakukan dengan cara angsuran, atau biasanya disebut kredit. Yang jadi persoalannya, di antara masalah mu'amalah yang menjadi pertentangan di antara para pemikir adalah transaksi jual beli emas secara kredit yang ditawarkan oleh lembaga keuangan syari'ah. Dengan cara cicilan akibat dibolehkannya jual beli kredit emas oleh Dewan Syari'ah Nasional dalam fatwanya No. 77/DSN-MUI/2010.

Dengan dikeluarkannya fatwa No. 77/DSN-MUI/2010 yang membolehkan jual beli emas secara kredit atau bertempo bertolak belakang dengan hadits Nabi saw. Diterangkan secara jelas bahwa jual beli emas harus dilakukan secara tunai.

Nabi saw bersabda :



Artinya: "(jual beli) emas dengan emas, perak dengan perak, gandum dengan gandum, kurma dengan kurma, garam dengan garam, sama dan sejenis serta secra tunai. Jika jenisnya berbeda, juallah sekehendak kali jika dilakukan secara tunai '(H.R. Bukhari Dan Muslim) (Bulughul Maram:170)

Menanggapi hadist di atas, Imam Syaukani menjelaskan tidak boleh menjual barang ribawi dengan barang ribawi dengan barang ribawi lainnya, kecuali secara tunai . tidak boleh menjualnya secara tempo lainnya, meskipun keduanya berbeda jenis dan ukuran, misalnya emas dengan perak, gandum dengan jawaaut (syair) (Ahmad Hassan ,2000: 417) 
Maka pengumpulan data dalam

\section{METODOLOGI PENELITIAN}

\section{Desain Penelitian}

Pada penelitian ini penulis menggunakan desain penelitian pustaka (library reseach) yaitu jenis penelitian yang menjadikan bahan pustaka menjadi sumber data utama, baik primer maupun sekunder (Dudung Abdurrahman, 1998: 26). Artinya penelitian inididasarkan pada data-data tertulis berbentuk buku, kitab fatwa, artikel yang berhubungan dengan fatwa DSN-MUI NO. 77/ DSN-MUI/IV/2010 tentang jual beli emas secara kredit. Berdasarkan objek penelitian ini, maka metode penelitian yang digunakan adalah metode penelitian normatif atau metode penelitian kepustakaan.

\section{Jenis data}

Berdasarkan objek penelitian dalam penelitian hukum normatif, maka jenis data yang digunakan penulis dalam penelitian ini adalah normatif, maka jenis data dalam penelitian ini menggunakan data tertulis baik berupa ayat-ayat Al-Qur'an, Hadist dan fatwa DSN-MUI, buku-buku, kitab-kitab para ulama', artikel dan lain-lain.

\section{Sumber Data}

Karena penelitian ini menggunakan jenis penelitian pustaka dengan menggunakan sumber data primer dan sumber data sekunder sehingga data-data yang dibutuhkan diambil dari buku-buku, jurnal, artikel, dan karya ilmiah lainya. penelitian ini dibagi menjadi dua, yaitu sumber data yang mengikat (primer) dan sumber data yang tidak mengikat (sekunder) sebagai berikut :

a) Data Primer

Data primer adalah data yang berkaitan langsung dengan kajian penelitian. Pengumpulan dari data primer merupakan bagian integral dari proses penelitian yang digunakan untuk pengambilan keputusan kesimpulan. Data primer ini diperoleheh langsung dari pendapat para fuqaha' dari Al-Qur'an, AsSunnah, kaidah fiqh dan ushul fiqh

b) Data Sekunder

Adalah sumber data yang diperoleh dari buku-buku yang akan mendukung pendalam dalam data primer kitab-kitab ulama', buku-buku, artikel dan dan jurnal.

\section{Analisis Data}

Metode analisis yang digunakan dalam penelitian ini adalah analisis dedukatif, yaitu memaparkan teori-teori jual beli, laranganlarangan jual beli, pendapat-pendapat ulama' tentang jual beli kredit, penarikan hukum para ulama dari sumber Al-Qur'an dan Hadist menggunakan metode ijtihad yaitu ijma', dan Qiyas maupun dalil yang yang kemudian dengan teori-teori yang berkenaan dengan objek penelitian.

\section{PEMBAHASAN}

Jual Beli Emas Secara Kredit Perspektif Hukum Islam 
Dalam praktek ekonomi, islam memberikan kebebasan yang sangat luas kepada setiap individu untuk melakukan transaksi dengan mengoptimalkan penggunaan kaidah-kaidah Hukum Islam. Hal ini disebabkan karena kegiatan ekonomi merupakan persoalan mu'amalah bukan ibadah (dalam pengertian khusus). Kaidah fiqh mengungkapkan :

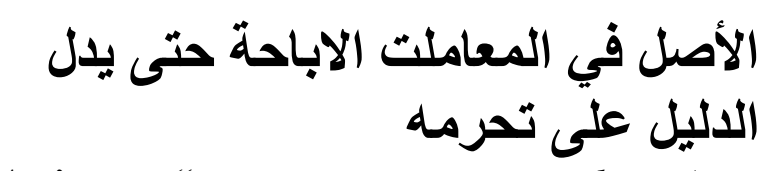

Artinya: "orang-orang yang makan (mengambil) riba' tidak dapat berdiri melainkan seperti berdirinya orang yang kemasukan syaitan lantaran (tekanan) penyakit gila. Keadaan mereka yang demikian itu, adalah disebbkan mereka berkata (berpendapat), sesungguhnya jual eli itu sama dengan riba', padahal Allah telah menghalalkan juak beli dan mengharamkan riba'. orang-orang yang telah sampai kepadanya laranagan dari tuhannya, lalu terus berhenti (dari mengambil riba), maka baginya apa yang telah diambilnya dahulu (sebelum datang larangan ); an urusannya (terserah) kepada Allah. Orang yang kembali (mengambil riba), maka orang itu adalah penhunipenghuni neraka; mereka kekal di dalamnya.

Ayat ini adalah nash yang umum yang tetap pada keumumannya karena masuknya alif dan lam. Penggunaan kata البيع memberikan makna bahwa segala bentuk jual beli adalah boleh (halal) apabila terpenuhi rukun-rukunya, syarat-syaratnya, terdapat sebab-sebabnya, dan tidak ada larangan melakukan jual beli, serta segala jenis jual beli yang dikenal sebagai jual beli menurut kebiasaan masyarakat baik dilakukan secara tunai maupun secara tangguh.

Namun, kebolehan jual beli tidak tunai/tangguh menjadi persoalan ketika menjadi objek pertukarannya adalah emas, sebagai praktik kredit emas dewasa ini, baik dilakukan individu maupun badan hukum. Sementara dalam hadits Nabi SAW. Telah dijelaskan secara implisit bagaimana larangan mentrakasaksikan emas dan perak secara tidak tunai/tangguh. Salah satu hadist yang diriwayatkan Abu Sa'id Al-Khudry Rasulallah SAW bersabda :

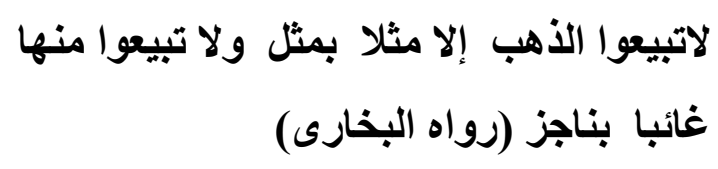

Artinya : "janganlah kalian menjual emas dengan emas kecuali dengan ukuran yang sama, dan janganlah menjual emas dengan ghaib dengan emas yang tunai( HR. Bukhari)

Hadist tersebut berkenaan dengan transaksi kaum muslimin dengan kaum yahudi. Ketika kaum yahudi kalah dalam perang khaibar, harta meraka diambil sebagai rampasan perang, termasuk di antaranya adalah perhiasan yang terbuat dari emas dan perak. Tentu saja perhiasan tersebut bukan gaya hidup kaum muslimin yang sederhana. Oleh karena itu, orang yahudi berusaha membeli perhiasan yang terbuat dari emas dan perak tersebut, yang akan dibayar dengan uang yang terbuat dari emas (dinar) dan uang yang terbuat dari perak (dirham). Jadi sebenarnya yang terjadi bukanlah jual beli, namun pertukaran barang sejenis. Emas 
ditukar dengan emas, perka ditukar dengan perak.

Pandangan Ulama Empat Mazhab Tentang Jual Beli Emas Secara Kredit

Para ulama yang mengharamkan jual beli emas secara kredit adalah para Imam Mazhab (Abu Hanifah, Imam Malik, Imam Syafi'i dan Hanbali). Dinyatakan dalam hadits Ubadah Bin Shamit ia berkata:

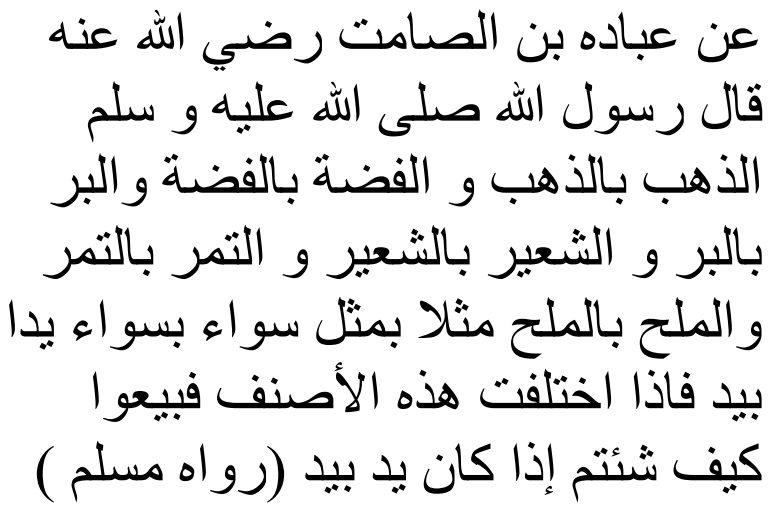

Artinya : “(jual beli) emas dengan emas, perak dengan perak, gandum dengan gandum, sya'ir dengan sya'ir, kurma dengan kurma, garam dengan garam, sama sejenis dan sejenis serta secara tunai. Jika jenisnya berbeda, juallah sekehendak kalian jika dilakukan secara tunai. (H.R. Muslim)

Benda-benda yang diharamkan yang di nashkan dengan ijma' ada enam yaitu: emas, perak,gandum, syair, kurma dan garam. Akan tetapi illat emas dan perak berbeda dengan yang lainnya. Menurut Imam Malik dan Imam Syafi'i dikerenakan illat barang dijadikan patokan harga dan benda-benda tersebutlah yang hanay bisa disamakan dengan uang. (Muhammad Hasby, 2001:340)

Jual Beli Emas Secara Kredit Menurut Dewan Syari'ah Nasional
Hukum jual beli emas secara kredit menurut Dewan Syari'ah Nasional berdasarkan fatwa no.77/DSN-MUI/2010 tentang jual beli emas secara tidak tunai adalah boleh, baik jual beli dengan cara biasa atau murabahah. Dewan Syari'ah Nasional berargumen bahwa :

1. Hadits-hadis yang menjelaskan tentang riba' pada emas dan perak adalah haditshadits mu'amalah (terdapat illat dalam penetapan hukumnya), sementara illat pengharaman emas dan perak dalam transaksi tersebut adalah tsaman sebagaimana pendapat mayoritas ulama fiqih. Maka ketika illat itu berubah, maka berubah pula hukumnya. Sebagaimana kaidah fiqih :

\section{الحكم يلور مع علته وجواد وعما}

Artinya: "hukum berputar (berlaku) bersama ada atau tidak adanya illat"

2. Tsaman (uang, harga) termasuk hasil budaya (urf), dimana budaya bisa menjadi dasar hukum selama budaya itu masih terus dilakukan dan tidak bertentangan dengan syari'ah.

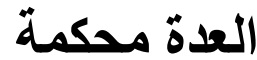

Artinya: Adat kebiasaan masyarakat dijadikan dasar penetapan hukum"

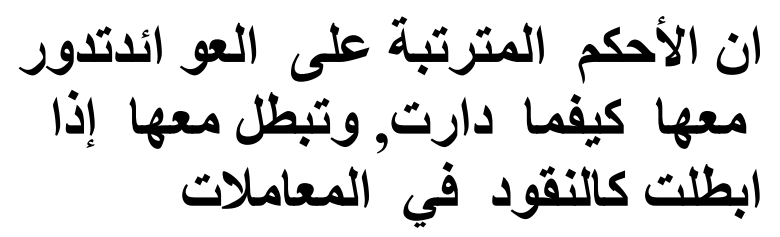

Artinya: "hukum yang didasarkan pada adat kebiasaan berlaku bersama adat 
tersebut dan batal bersama ketika adat itu batal seperti uang dalam mu'amalah".

Menurut kebiasaan umat saat ini, jelaslah emas tidak lagi dijadikan sebagai mata uang melainkan hanya sebagai perhiasan dan barang dagangan. Sedangkan kebiasaan umat (kesepakatan) pada saat ini menganggap mata uang yang berlaku adalah mata uang yang dikeluarkan oleh pemegang otoritas masing-masing negara. Sehingga hukum riba' pada emas dan perak tidak berlaku lagi.

Berdasarkan dalil-dalil yang dikemukakan oleh DSN-MUI, maka diahami bahwa ulama peserta rapat pleno sepakat bahwa fungsi emas dan perak sebagai mata uang saat itu (ketika hadits-hadits yang membicarakan riba emas dan perak) adalah hasil budaya masyarakat setempat. Dinar dan dirham yang berlaku pada saat itu bukanlah produk islam. Tetapi produk masyarakat Persia (Iran). Dalam hadits-hadits Nabi SAW. Tidak diketemukan ada dalil yang melarang menjadikan emas dan perak sebagaiuang. Bahkan Nabi SAW melakukan transaksi menggunakan emas dan perak. Perbuatan Nabi saw ini dalam hukum islam dikenal dengan istilah sunnah taqriyah.

Dengan begitu tidak ada kita jumpai dalil hadist Nabi yang memerintahkan secara eksplisit, yegas dan jelas bahwa uang itu harus terbuat dari emas dan perak. Bahkan sahabat Beliau Khalifah Umar bin Khattab pernah mewacanakan akan membuat uang dari kulit unta, tetapi usul beliu ditentang oleh para sahabat. Dengan alasan sekiranya beliau membuat uang dari kulit unta, maka tidak akan ada unta lagi di Madinah, karena masyarakat akan berlomba-lomba memotong unta mereka dan menjadikan kulitnya sebagai uang.

\section{Dasar Hukum Penetapan Fatwa Dsn-Mui}

\section{Tentang Jual Beli Emas Secara Kredit}

Dewan Syari'ah Nasional Majelis Ulama Indonesia (DSN-MUI) padafatwanya tersebut diatas dengan jelas menyatakan bahwa jual beli emas itu boleh (mubah) dengan syarat selama emas tidak menjadi alat tukar yangresmi, baik jual beli biasa maupun murabahah. Kemudian DSN memberikantiga batasan dalam keputusan hukum kebolehan jual beli emas tersebut yangmerupakan implikasi dari jual beli emas secara tidak tunai, yaitu tidak bolehbertambahnya harga jual selama perjanjian walaupun adanya penundaanpembayaran setelah jatuh tempo, hal ini karena emas selalu berfluktuasi harganya dalam jangka waktu tertentu.

Keputusan fatwa tersebut menggunakan beberapa dalil yang dijadikan dasar hukum oleh DSN. Oleh karena itu, untuk lebih jelasnya maka penulis akan mengkaji dan meneliti kembali dalil-dalil yang digunakan oleh DSN MUI dalam keputusannya tersebut. Dalil-dalil tersebutdi antaranya adalah sebagai berikut:

a. Al-qur'an: Ayat al-Qur'an yang digunakan sebagai landasan atau dasar hukum oleh DSN yaitu surah al-Baqarah 
ayat 275 , yang menerangkan secara umum tentang hukum jual beli dan riba

$$
\text { وأحل لله البيع وحرم الربؤا }
$$

Artinya :Allah telah menghalalkan jual beli dan mengharamkan riba". (QS. alBaqarah [2]: 275)

\section{b. Hadits Nabi SAW}

Hadis Nabi riwayat Ibnu Majah dan alBaihaqi dari Abu Sa'id al-Khudri:

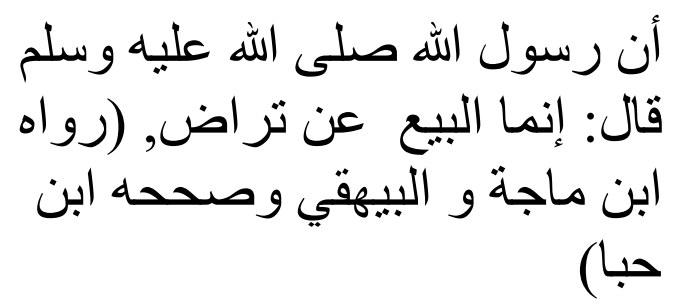

Artinya : Rasulullah SAW bersabda, "Sesungguhnya jual beli itu hanya boleh dilakukan atas dasar kerelaan (antara kedua belah pihak)." (HR. Ibnu Majah dan al-Baihaqi, dan dinilai Shahih oleh Ibnu Hibban) (DSN-MUI, 2010:2).

Hadits Nabi riwayat Muslim, Abu Dawud, Tirmidzi, Nasa`i, dan Ibnu Majah, dengan teks Muslim dari Ubadah bin Shamit, Nabi SAW bersabda:

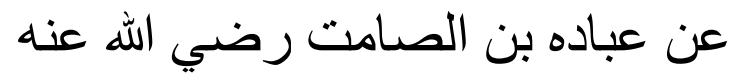
قال رسول الله صلى الله علبه و سلم

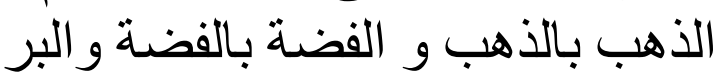
بالبر و الثتعير بالثُعير و التهر بالتمر

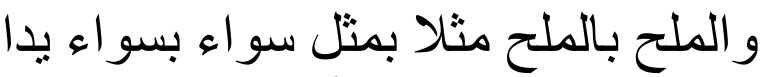
بيد فاذا اختلفت هذه الأصنف فبيعوا كيف شُئتم إذا كان بد بيد (رو اه مسلم)

Artinya : "(jual beli) emas dengan emas, perak dengan perak, gandum dengan gandum, sya'ir dengan sya'ir, kurma dengan kurma, garam dengan garam, sama sejenis dan sejenis serta secara tunai. Jika jenisnya berbeda, juallah sekehendak kalian jika dilakukan secara tunai. (H.R. Muslim)

Hadis Nabi riwayat Muslim, Tirmidzi, Nasa'i, Abu Daud, Ibnu Majah, dan Ahmad, dari Umar bin Khatthab, Nabi SAW bersabda:

$$
\text { الذهب بالورق ربا إلا هاء و هاء... }
$$

Artinya : "(Jual beli) emas dengan perak adalah riba kecuali (dilakukan) secara tunai." (HR. Muslim)

Hadits Nabi riwayat Muslim dari Abu Sa'id al-Khudri, Nabi SAWbersabda:

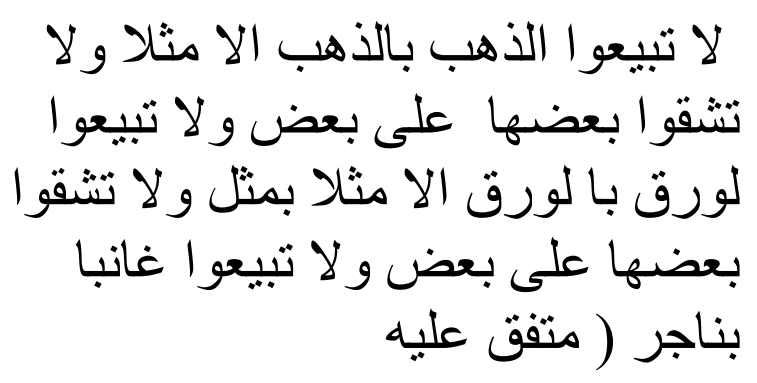

Artinya : "Janganlah kamu menjual emas dengan emas kecuali sama (nilainya) dan janganlah menambahkan sebagian atas sebagian yang lain; janganlah menjual perak dengan perak kecuali sama (nilainya) dan jangan menambahkan sebagian atas sebagian yang lain; dan janganlah menjual emas dan perak tersebut yang tidak tunai dengan yang tunai."

Hadits Nabi riwayat Muslim dari Bara' bin 'azib dan Zaid bin Arqam:

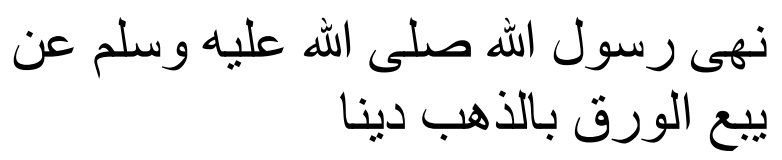

Artinya: "Rasulullah SAW melarang menjual perak dengan emas secara piutang (tidak tunai)."

Hadits Nabi riwayat Tirmidzi dari 'Amr bin 'Auf al-Muzani, NabiSAW bersabda: 

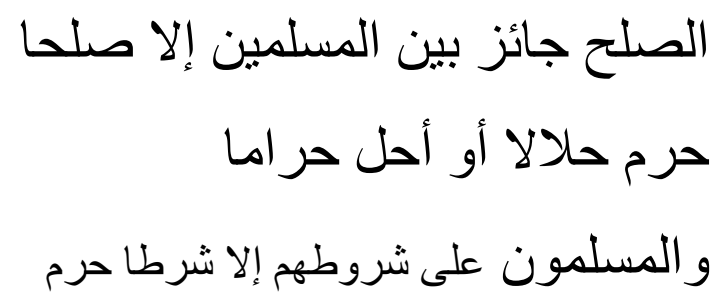

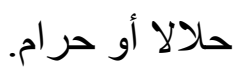

Artinya: "Perdamaian (musyawarah mufakat) boleh dilakukan di antara kaum muslimin kecuali perdamaian yang mengharamkan yang halal atau menghalalkan yang haram; dan kaum muslimin terikat dengan syaratsyarat mereka kecuali syarat yang mengharamkan yang halal atau menghalalkan yang haram. (DSN-MUI, $2010: 2$ )

Dengan melihat keputusan fatwa serta dalil-dalil yang digunakanoleh DSN MUI diatas, baik berupa al-Qur'an, Hadits, Kaidah Ushul, Kaidah Fiqh, dan Pendapat Ulama, penulis melihat bahwa DSN dalam keputusannya bahwa emas boleh dijualbelikan dengan cara tidak tunailebih cendrung kepada pendapat sebagian ulama yang membolehkan dengan istidlal yang berbeda.

Adapun pendapat ulama yang dijadikan sandaran oleh DSN yang paling menonjol adalah apa yang diungkapkan oleh Dr. Khalid Mushlih dalam al-Hukmu Bai' alDzahab bi al-Nuqud bi al-Taqsith Syaikh 'Abd Hamid Syauqiy al-Jibaliy dalam Bai' alDzahab bi al-Taqsith. Dimana kesemuanya berawal dari pendapat Ibnu Taimiyyah dan Ibnu Qayyim al Jauziyah, yang membolehkan jual beli emas berupa perhiasan secara tidak tunai. Dengan alasan karena emas berupa perhiasan saat ini sudah beralih fungsi menjadi barang (sil'ah) dan telah keluar sifatnya sebagai barang ribawi (tsamaniyah), sehingga syarat harus tunai (taqabudh) tidak berlaku lagi. Karena emas dalam konteks saat ini dalam segala jenisnya lebih difungsikan sebagai komoditi dan tidak lagi sebagai alat pembayaran (uang). Adapun hadits-hadits larangan memperjualbelikan emas secara tidak tunai adalah hadits hukum yang mengandung illat bahwa emas dan perak merupakan media pertukaran dan transaksi di masyarakat. Dalam konteks masa kini, saat fungsi itu tak lagi berlaku maka tiada pula hukum tersebut. Berdasarkan kaidah fikih al hukmu yadurru ma'a 'illathi wu judan wa 'adaman (hukum berlaku ber sama dengan illat-nya, baik ada maupun tiada). Argumen lain yang dikemukakan kalangan yang membolehkan ialah prinsip kemudahan yang menjadi ruh dari syariat Islam. Saat ini, bila larangan angsuran atau anggunan membeli emas atau perak maka bisa menyebabkan kemaslahatan manusia terancam dan akan mengalami kesulitan. Melihat dari hal-hal tersebutlah musyawarah DSN kemudian memilih (cenderung) kepada pendapat yang membolehkan.

Sementara mayoritas ulama dari kalangan ulama madzhab seperti Imam asySyafi'i serta ulama-ulama Syafi'iyah dan lainnya maupun dari kalangan ulama kontemporer seperti Syaikh Muhammad bin Shalih al-Utsaimin berpendapat bahwa jual beli emas dengan cara kredit hukumnya adalah haram. Dengan dasar keumuman dari hadits-hadits Nabi SAW yang melarang 
memperjualbelikan emas dengan cara tidak tunai baik emas tersebut digunakan sebagai mata uang ataupun tidak. Sebagaimana yang telah kemukakan dalil-dalil mereka pada bab sebelum ini.

\section{SIMPULAN}

Jual beli secara tunai mempunyai masa yang luas dan tidak terbatas pada penangguhan pembayaran. Dalam Isalm transaksi ini disebut dengan bai' muajjal bil murabahah, jual beli dengan pembayaran tangguh disertai penambahan harga yang lebih tinggi dari pada harga secara tunai secara tidak tunai, para sarjana hukum Islam berbeda pendapat. Pertama: Haram. Berdasarkan keumuman hadits riba pada emas dan perak. Kedua: boleh. Argumen ulama pendukung pendapat ini adalah bahwa haditshadits tersebut adalah dalil muallalah, hukum yang berlaku berdasarkan adanya illat maka ketika illat berubah maka berubah pula hukumnya. Dan pendapat ini dimana emas dan perak tidak lagi dianggap sebagai uang melainkan hanya sebagai perhiasan dan barang.

Kesepakatan ulama peserta rapat pleno Dewan Syari'ah Nasional menyatakan bahwa jual beli emas secara tidak tunai adalah boleh. Hal ini didasarkan pada pemahaman ulama peserta rapat pleno Dewan Syari'ah Nasional bahwa penggunaan emas dan perak sebagai uang pada zaman sahabat adalah bagian dari budaya. Budaya (urf/'adah) dapat dijadikan sebagai landasan hukum selama budaya tersebut masih tetap hidup di tengah-tengah masyarakat tersebut. Serta budaya tersebut tidak bertentangan dengan Al-Qur'an dan hadist. Pendapat Dewan Syari'ah Nasional yang yang notabenenya berdasarkan pendapat mereka pada pendapat-pendapat ulama dan menyesuaikan pendapat mereka dengan situasi ummat khususnya di Indonesia lebih tepat dan lebih mendasarkan inilah yang mendekati kepada kemaslahatan ummat.

\section{DAFTAR PUSTAKA}

Abdullah Saeed. 2008. Bank Islam Dan Bunga, Yogyakarta: Pustaka Pelajar.

Abdul aziz azzam. 2010. Figh Mu'amalah, Sistem Transaksi Dalam Islam, Ed.1, Cet. 1, Jakarta: Hamzah.

Abdul Wahhab Khalaf. 2003. Ilmu Ushul Fiqh, Jakarta: Pustaka Amani.

Ahmad djazuli. 2001. Kaida-kaidah fikih, Jakarta: Kencana

Ahmad Hasan. 2000. Terjamahan bulugul maram, Bandung : Diponegoro

Departemen Agama Republik Indonesia. 2010. Al-Qur'an Dan Tejemahannya. Jakarta: DEPAG.

Fatwa DSN-MUI NO 77/DSN-MUI/2010 Tentang Jual Beli Emas Secara Tidak Tuna.

Lukman Al Hakim, Muslihun Muslim. 2010. Muqaranah Fi Al- Mu'amalah. Yogyakarta: Kurnia Kalam Semesta.

Mardani. 2010. Hukum Ekonomi Syari'ah Di Indonesia. Jakarta: Reflika Aditama.

Muhammad Muslehuddin. 2004. Sistem Perbankan Dalam Islam. Jakarta: Rineka Cipta . 
Muchlis Usman. 2002. Kaidah-Kadidah Ushuliyah dan Fiqhiyah. Jakarta: Raja Grafindo Persada.

Rachman F Dkk Maya F. 2013. Manajemen Perkreditan Bank Umum: Teori Masalah Kebijakan Dan Aplikasi.. Bandung: Alfabeta.

Syarifuddin Anwar, Misbah Musthafa. 2007. Tejemah Kifayatuk Akhyar. Surabaya:: Bima Iman 